\title{
POLINIZAÇÃO DA PEREIRA-PORTUGUESA EM BOM RETIRO-SC, BRASIL ${ }^{1}$
}

\author{
ANDRÉ AMARILDO SEZERINO² \& AFONSO INÁCIO ORTH ${ }^{3}$
}

RESUMO - O objetivo do trabalho foi verificar e confirmar experimentalmente o sistema reprodutivo preferencial da pereira-portuguesa (Pyrus communis L. cv. Rocha) por meio de avaliações da quantidade e da viabilidade dos grãos de pólen, do número de óvulos por flor e da razão pólen/óvulo, além da frutificação efetiva em diferentes cruzamentos controlados. Os resultados mostram que a cv. Rocha produziu menos grãos de pólen e menos óvulos por flor do que as cvs. Housui e Packham's Triumph utilizadas como polinizadoras nesta área. A razão pólen/óvulo média das três cultivares foi de 17.015,05, o que as classifica como xenogâmicas. Os grãos de pólen da cv. Packham's Triumph apresentaram o maior percentual de germinação comparativamente à 'Housui' e 'Rocha'. Os resultados dos cruzamentos controlados mostraram que a cv. Rocha apresentou elevada frutificação efetiva quando ocorre polinização cruzada, mesmo sem a aplicação exógena de giberelina. Contudo, a aplicação deste regulador promoveu aumento significativo na frutificação efetiva de flores sob polinização livre, mas seu efeito foi variável entre os ciclos produtivos. A formação de frutos estenoespermocárpicos foi estimulada com a autopolinização e a aplicação exógena da giberelina sintética. Conclui-se que a pereira 'Rocha' é xenogâmica e apresenta elevada frutificação efetiva quando adequadamente polinizada com pólen de 'Housui' e 'Packham's Triumph', sendo a aplicação de ácido giberélico a $20 \mathrm{mg} \mathrm{L}^{-1}$ uma alternativa em caso de polinização deficiente.

Termos para indexação: Pyrus communis, 'Rocha', frutificação efetiva, giberelina, polinização.

\section{POLLINATION OF THE PORTUGUESE PEAR IN BOM RETIRO-SC, BRAZIL}

\begin{abstract}
The objective of this study was to verify and confirm experimentally the reproductive system of the Portuguese pear (Pyrus communis L. cv. Rocha) through assessments of the amount and viability of pollen grains, the number of ovules per flower and pollen/ovule ratio, in addition to the quantification of the fruit set in different controlled pollination systems. The results show that cv. Rocha produced fewer pollen grains and ovules per flower than the cvs. Housui and Packham's Triumph, which were used as pollen donor cultivars in this area. The average pollen/ovule ratio of the three cultivars was 17.015,05, which classifies them as xenogamic. The pollen grains of the cv. Packham's Triumph showed the highest percentage of germination compared to 'Housui' and 'Rocha'. The results of the controlled pollination treatments show that cv. Rocha present a high fruit set when cross-pollination occurs, even without the exogenous application of growth regulators. However, the application of a synthetic gibberellin promotes a significant increase in fruit set in open pollinated flowers, but its effect was variable in different years. The formation of stenospermocarpic fruits probably is stimulated with pollination and exogenous application of a synthetic gibberellin. We concluded that 'Rocha' pear is xenogamic and set a high fruit yield when properly pollinated with pollen from 'Housui' and 'Packham's Triumph', and the application of gibberellic acid is an alternative in case of poor pollination .
\end{abstract}

Index terms: Pyrus communis, 'Rocha', fruit set, gibberellin, pollination.

\footnotetext{
1'(Trabalho 209-14). Recebido em: 18-07-2014. Aceito para publicação em: 23-04-2015.

${ }^{2}$ Engenheiro Agrônomo, Pesquisador em Fitotecnia - Estação Experimental de Caçador - Empresa de Pesquisa Agropecuária e Extensão Rural de Santa Catarina - SC. E-mail: andresezerino@epagri.sc.gov.br

${ }^{3}$ Engenheiro Agrônomo, Prof. Phd. Departamento de Fitotecnia - Universidade Federal de Santa Catarina - SC. E-mail: afonso.orth@ ufsc.br
} 


\section{INTRODUÇÃO}

A pereira é cultivada em diversos países, o que a torna fruta de grande aceitação e importância nos mercados internacionais. A produção mundial, em 2011, foi de aproximadamente 23,9 milhões de toneladas. Os principais países produtores foram China $(66,7 \%$ do total produzido, com 15.945 .000 t); Itália (3,87\%, com 926.542 t); Estados Unidos (3,57\%, com 853.407 t); Argentina (2,89\%, com 691.270 t) e Espanha $(2,10 \%$, com 502.209 t). No mesmo ano, o Brasil produziu apenas 20.532 toneladas, $0,08 \%$ do total mundial (FAO, 2013a).

Dentre as frutas de clima temperado, a pera é a terceira mais consumida no Brasil, sendo apenas superada pela maçã e pela uva (IBGE, 2010). Todavia, devido à baixa produção nacional, é a fruta fresca importada em maior quantidade pelo País (FIORAVANÇO, 2007; FAO, 2013b). Dentre as cultivares importadas, destacam-se as europeias, tais como: Williams, D'Anjou, Packam's Triumph e Rocha (NAKASU; FAORO, 2003). A pera Rocha, ou pereira-portuguesa, é uma cultivar obtida casualmente de semente, em 1836, no Conselho de Sintra, na região do oeste de Portugal. É uma variedade medianamente exigente em frio hibernal (550 horas de frio abaixo de $7,2^{\circ} \mathrm{C}$ ), com tendência para produzir frutos partenocárpicos (ANP, 2009). É cada vez mais conhecida mundialmente devido às características de seus frutos, que apresentam excelente resistência ao manuseio e ao transporte, e capacidade de conservação prolongada sem perda das qualidades organolépticas (SILVA et al., 2005; SOUSA, 2012).

A maioria das cultivares de pereiras produtoras de frutas de alta qualidade não tem boa adaptação às condições climáticas da região Sul do Brasil, principalmente devido ao frio hibernal insuficiente para a satisfação da dormência (PETRI et al., 2001). Além disso, por ser alógama devido à incompatibilidade gametofítica, a maioria das cultivares europeias não produz frutos com sementes sem que ocorra a presença de insetos polinizadores durante o florescimento (BENEDEK, 1996), prejudicando assim sua frutificação efetiva.

A frutificação efetiva, como resultado de polinização bem-sucedida, é requisito para se obter alto rendimento na produção das fruteiras de clima temperado (GUERRA et al., 2009).

$\mathrm{Na}$ pereira, para superar a barreira da incompatibilidade gametofítica, proporcionando fecundação satisfatória, é necessário que haja transferência entre polens de genótipos compatíveis quanto à série alélica "S" e que seja intermediada por insetos polinizadores (FAORO, 2009).

Devido a isto, este trabalho teve o objetivo de verificar e confirmar experimentalmente o sistema reprodutivo preferencial da pereira 'Rocha' por meio de estudos de sua biologia reprodutiva em uma área de produção comercial no Sul do Brasil.

\section{MATERIAL E MÉTODOS}

Os estudos foram conduzidos em área de produção comercial, localizada no município de Bom Retiro-SC, a altitude de 915 metros acima do

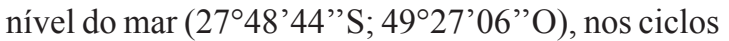
produtivos de 2012/2013 e 2013/2014. Utilizou-se no estudo da cultivar Rocha como produtora de frutos e das cultivares Housui e Packham's Triumph como polinizadoras.

Foi quantificado o número de grãos de pólen por flor de acordo com a metodologia proposta por Kearns e Inouye (1993) e o número de óvulos determinado em 50 flores, por meio do corte transversal do ovário sob microscópio estereoscópico (16X), seguido da contagem dos mesmos. Para inferir o sistema reprodutivo preferencial das cultivares, foi calculada a razão pólen/óvulo (P/O), a qual foi determinada seguindo-se a fórmula proposta por Cruden (1977), em que a razão (P/O) é obtida por meio da divisão da média do número de grãos de pólen pelo número médio de óvulos por flor.

A viabilidade dos grãos de pólen das cultivares Rocha, bem como de suas polinizadoras, foi avaliada por meio da germinação in vitro em meio de cultura ( $1,0 \mathrm{~g} \mathrm{~L}^{-1}$ de Ágar, $20 \%$ de sacarose e $40 \mathrm{mg} \mathrm{L}^{-1} \mathrm{de}$ ácido bórico), mantido em placas de Petri ${ }^{\circledR}(20 \mathrm{~mL}$ placa $\left.^{-1}\right)$, as quais foram mantidas em temperatura ambiente $\left(18 \pm 2,0^{\circ} \mathrm{C}\right)$ (adaptado de DANTAS et al., 2005). Foi considerado germinado o grão de pólen que emitiu tubo polínico com comprimento igual ou superior ao seu diâmetro A porcentagem de grãos de pólen germinados foi obtida pela contagem em microscópio óptico (Studar Lab, com magnificação de 100x), constituindo avaliação de 100 grãos por repetição, sendo realizadas 8 repetições. As avaliações foram realizadas 4 horas após a semeadura dos grãos de pólen no meio.

O delineamento experimental foi em fatorial $2 \times 3$ (ciclo produtivo $\times$ cultivar), para avaliação do número de grãos de pólen por flor, número de óvulos por flor, a razão pólen/óvulo e a germinação dos grãos de pólen.

Para a determinação do sistema reprodutivo preferencial da cv. Rocha, foram realizados cruzamentos controlados entre os dias 12 e 18 09-2012 (ciclo produtivo 2012/2013) e entre os 
dias 22 e 27-09-2013 (ciclo produtivo 2013/2014), segundo: 1) Polinização livre em área com 'Housui' plantada como polinizadora e sem tratamento com giberelina; 2) Autopolinização espontânea sem tratamento com giberelina (flores em pré-antese foram protegidas com sacos de papel kraft); 3) Partenocarpia sem tratamento com giberelina (flores foram emasculadas em pré-antese e protegidas com sacos de papel kraft); 4) Polinização cruzada manual com pólen de Packham's Triumph e sem aplicação de giberelina (flores da cv. Rocha em pré-antese foram emasculadas, polinizadas com auxílio de um pincel $\mathrm{n}^{\circ} 2$ e protegidas com sacos de papel kraft. O pólen de 'Packham's Triumph' foi coletado de flores em préantese, três dias antes da polinização, e seco em estufa a $28 \pm 2,0^{\circ} \mathrm{C}$ por 48 horas); 5) Polinização cruzada manual com pólen de 'Housui' e sem aplicação de giberelina (idem ao tratamento anterior, mudando a fonte de pólen); 6) Autopolinização manual sem aplicação de giberelina (flores da cv. Rocha foram emasculadas em pré-antese, polinizadas com auxílio de um pincel $\mathrm{n}^{\circ} 2$ e protegidas com sacos de papel kraft. O pólen de 'Rocha' foi coletado de flores em pré-antese das mesmas plantas polinizadas, três dias antes da polinização e seco em estufa a $28 \pm 2,0^{\circ} \mathrm{C}$ por 48 horas); 7) Polinização livre em área com 'Housui' como polinizadora e tratamento com giberelina (flores em pré-antese foram marcadas e pulverizadas com ácido giberélico $\left.20 \mathrm{mg} \mathrm{L}^{-1}\right)$; 8) Autopolinização espontânea e tratamento com giberelina (flores em pré-antese foram pulverizadas com ácido giberélico $20 \mathrm{mg} \mathrm{L}^{-1}$ e protegidas com sacos de papel kraft); 9) Partenocarpia e tratamento com giberelina (flores foram emasculadas em pré-antese, pulverizadas com ácido giberélico $20 \mathrm{mg} \mathrm{L}^{-1}$ e protegidas com sacos de papel kraft); 10) Polinização cruzada manual com pólen de 'Packham's Triumph' e tratamento com giberelina (flores da cv. Rocha em pré-antese foram emasculadas, polinizadas com auxílio de um pincel $\mathrm{n}^{\circ} 2$, pulverizadas com ácido giberélico $20 \mathrm{mg}$ $\mathrm{L}^{-1} \mathrm{e}$ protegidas com sacos de papel kraft. O pólen de 'Packham's Triumph' foi preparado conforme descrito no tratamento 4); 11) Polinização cruzada manual com pólen de 'Housui' e tratamento com giberelina (idem ao tratamento anterior, mudando a fonte de pólen); 12) Autopolinização manual e tratamento com giberelina (flores da cv. Rocha foram emasculadas em pré-antese, polinizadas com auxílio de um pincel $n^{\circ}$, pulverizadas com ácido giberélico $20 \mathrm{mg} \mathrm{L}^{-1}$ e protegidas com sacos de papel kraft. O pólen de 'Rocha', conforme descrito no tratamento 6); e 13) Polinização livre em área com 'Packham's Triumph' como polinizadora e tratamento com giberelina (flores em pré-antese foram marcadas e pulverizadas com ácido giberélico $20 \mathrm{mg} \mathrm{L}^{-1}$ ). A aplicação de ácido giberélico foi realizada utilizando-se do produto comercial ProGibb ${ }^{\circledR}(10 \%$ de ingrediente ativo - $\mathrm{m} / \mathrm{m}$ ) nas plantas inteiras, com turboatomizador tratorizado (Jacto Arbus 2000), com volume de calda de $800 \mathrm{~L} \mathrm{ha}^{-1}$.

Foram marcadas e acompanhadas 120 flores em cada cruzamento, totalizando 1.560 flores em cada ciclo produtivo. Para a avaliação da frutificação efetiva, em cada tratamento, foram marcadas 3 gemas com 4 flores por planta, em 10 plantas, sendo considerada cada gema uma repetição $(\mathrm{N}=30)$. Para a classificação da fixação de frutos, foi adotada a seguinte escala: a) sem frutos: $0 \%$ de fixação; b) muito baixa: 0,1 a 1,0\% de fixação; c) baixa: 1,1 a $4,0 \%$; d) média: 4,1 a $8,0 \%$; e) alta: 8,1 a $15 \%$; f) muito alta: 15,1 a 30,$0 ; \mathrm{g}$ ) extremamente alta: 30,1 a 60\% (NYÉKI; SOLTÉSZ, 1998; FAORO, 2009).

Foi avaliada a frutificação efetiva (fruit set), 30 dias após a implantação dos tratamentos e por ocasião da colheita. O delineamento experimental foi o inteiramente casualizado, sendo os dados transformados em $\log (x+2)$. Foi realizada a análise de variância paramétrica e o teste de Tukey para a comparação das médias.

\section{RESULTADOS E DISCUSSÃO}

A interação ciclo produtivo x cultivar mostrou efeito significativo para o número de grãos de pólen por flor (Tabela 1); número de óvulos por flor (Tabela 2); razão pólen/óvulo (Tabela 3), sendo o mesmo não obtido para germinação in vitro dos grãos de pólen, uma vez que somente teve significância para cada fator isolado (Tabela 4).

No primeiro ciclo produtivo, de 2012/2013, a cultivar Housui apresentou maior quantidade de grãos de pólen em comparação às demais, sendo o mesmo não obtido no ciclo de 2013/2014, que teve 'Packham's Triumph' com média superior (Tabela 1) às outras duas cultivares. Quanto aos ciclos produtivos, os resultados obtidos com 'Rocha' não diferiram estatisticamente entre si, comparando-se 2012/2013 com 2013/2014. Todavia, para 'Housui', a maior média foi obtida no primeiro ciclo (2012/2013) e para 'Packham's Triumph' no segundo (2013/2014) (Tabela 1). As mesmas respostas estatísticas foram obtidas para a razão pólen/óvulo nas flores das três cultivares, nos dois ciclos produtivos (Tabela 3 ).

A produção de grandes quantidades de pólen é característica desejável, uma vez que permite maior probabilidade de ocorrência de polinização cruzada. Além de fonte de pólen para a fertilização dos óvulos, uma vez que as flores da pereira apresentam 
baixa secreção de néctar e este com baixo teor de açúcar (FREE, 1993), o pólen é o recurso floral mais importante para atrair os insetos polinizadores (BENEDEK, 1996).

Dumanoglu e Celik (1994) observaram, em 19 cultivares de pereira, médias de grãos de pólen por flor variando entre 139.250,8 (cv. Bonne Louise Davrance) até 497.926,3 (cv. Willians). Faoro (2009) observou média de 159.900 grãos de pólen por flor na cv. Housui, em Caçador-SC, no ciclo de 2007/2008. Castro et al. (2012) observaram média de 73.689 grãos de pólen flor ${ }^{-1}$ na cv. Rocha e 81.542 na cv. Packham's Triumph, no ciclo de 2010/2011, em São Francisco de Paula-RS. Neste trabalho, o número de grãos de pólen por flor foi similar ao descrito na literatura (FAORO, 2009; CASTRO et al., 2012, respectivamente), com a pereira 'Rocha', no ciclo de 2012/2013, e 'Housui' em 2013/2014. Já 'Packham's Triumph' apresentou quantidade superior ao citado por Castro et al. (2012), sendo esta de aproximadamente $97,3 \%$ e $163,6 \%$ superior em 2012/2013 e 2013/2014, respectivamente. Esta diferença pode estar associada ao fato de que algumas fruteiras de clima temperado com elevada necessidade de frio hibernal, quando cultivadas em regiões com ocorrência de menor número de horas de frio, em comparação ao exigido pela gema, podem produzir flores de menor tamanho, anteras menores e baixa quantidade de grãos de pólen quando comparadas com locais com maior acúmulo de horas de frio (FAORO, 2009). Dependendo da cultivar, temperaturas muito baixas durante o inverno também podem diminuir a formação de grãos de pólen (JACKSON, 2003).

O número de óvulos por flor, na cultivar Rocha, mostrou superioridade no ciclo de 2013/2014, tendo o mesmo não ocorrido com 'Housui' e 'Packham's Triumph', já que as médias entre os ciclos se igualaram estatisticamente (Tabela 2). Já dentro de cada ciclo produtivo, a pereira 'Rocha' apresentou menor número de óvulos por flor do que as demais cultivares em 2012/2013 (Tabela 2). Já em 2013/2014, as médias entre as cultivares para essa variável igualaram-se estatisticamente entre si (Tabela 2).

De maneira geral, é descrito que as flores de pereira apresentam ovários ínferos, contendo cinco carpelos com dois óvulos por carpelo, os quais podem formar, no máximo, dez sementes por fruto (FREE, 1993; BELL et al., 1996; LEITE; SOUZA, 2003). Contudo, observou-se que, na cv. Rocha, houve variação no número de óvulos por flor entre os ciclos, a qual está possivelmente associada a fatores climáticos durante a diferenciação floral, além de fatores como restrições edáficas, a ocorrência de déficit hídrico e o manejo de adubação, que podem estar atuando concomitantemente para a formação de flores de menor tamanho, com menos carpelos e óvulos por flor.

Segundo a classificação proposta por Cruden (1977), as pereiras 'Rocha', 'Housui' e 'Packham's Triumph' podem ser classificadas como xenogâmicas, ou seja, seu sistema reprodutivo é dependente de polinização cruzada, apresentando dicogamia ou auto-incompatibilidade, o que as torna dependentes de agente polinizador para que haja fertilização e posterior formação de sementes. De acordo com os dados levantados neste estudo, é possível afirmar que a pereira 'Rocha' apresenta a protoginia como forma de dicogamia, uma vez que foi observada frutificação nos cruzamentos controlados realizados em flores na pré-antese, o que confirma que os estigmas estavam receptivos antes da deiscência das anteras, sendo esta classificação válida como método para inferir o sistema reprodutivo preferencial deste material genético.

Para uma cultivar ser indicada como polinizadora, ela precisa produzir não só pólen em quantidade suficiente, mas que o mesmo tenha germinação adequada (SOUZA; RASEIRA, 1998). Segundo Leite e Souza (2003), os grãos de pólen devem apresentar viabilidade de, no mínimo, 50\%.

De acordo com a Tabela 4, a porcentagem de germinação dos grãos de pólen obtida no ciclo de 2012/2013 foi superior em relação à de 2013/2014. Na média dos dois ciclos, a cv. Packham's Triumph apresentou porcentagem de germinação significativamente superior em relação à 'Rocha' e 'Housui', sendo que estas duas se assemelharam entre si.

Na média dos dois anos, apenas a cv. Packham's Triumph apresentou percentual de germinação considerado como adequado $(50,6 \%)$. Souza (1999) observou germinação de 41,27\% dos grãos de pólen da cv. Housui após três horas, a $25^{\circ} \mathrm{C} \pm 2{ }^{\circ} \mathrm{C}$. Gonçalves (2008) observou 50,0\% de germinação do pólen de 'Packham's Triumph' após quatro horas de incubação.

Muitos fatores podem interferir na germinação dos grãos de pólen in vitro, entre eles destacam-se: o genótipo da planta, o momento da coleta, as condições de armazenagem, a composição do meio de cultura e a temperatura no momento da germinação. DeConti et al. (2013) citaram que as diferenças de viabilidade do pólen de um ciclo para outro podem estar relacionadas ainda a fatores como estresse hídrico, manuseio do pólen desde a coleta até o teste de germinação, assim como as condições nutricionais 
da planta. Em algumas cultivares, temperaturas elevadas durante a primavera podem induzir a produção de pólen estéril, enquanto temperaturas muito baixas durante o inverno podem diminuir sua viabilidade (JACKSON, 2003). Petri et al. (2013) citam que o acúmulo de frio no ciclo de 2013/2014, considerando as Unidades de Frio (UF) pelo modelo Carolina do Norte Modificado, foi superior à média histórica em relação ao ciclo anterior, em todos os locais monitorados em Santa Catarina, o que indica ter afetado a microsporogênese e, consequentemente, a viabilidade dos grãos de pólen.

A análise dos resultados dos diferentes tratamentos de polinização evidenciou que a frutificação efetiva na cv. Rocha está estreitamente relacionada com a forma de como foi realizada (Tabela 5). No ciclo de 2012/2013, as maiores frutificações efetivas, 30 dias após a polinização, e de frutos colhidos (\%) foram nos tratamentos partenocarpia com uso de giberelina; de polinização cruzada manual com pólen de 'Packham's Triumph' ou de 'Housui' com e sem giberelina; com polinização livre em área com 'Packham's Triumph' com giberelina ou de 'Housui' sem giberelina. A mesma superioridade foi obtida no ciclo de 2013/2014 apenas para a polinização cruzada manual com pólen de 'Packham's Triumph' ou de 'Housui' com e sem giberelina (Tabela 5).

Foi possível observar que os tratamentos de polinização cruzada manual sem a aplicação de giberelina apresentaram elevada frutificação efetiva. Quando comparados com o tratamento de polinização livre sem aplicação giberelina, fica evidente que os grandes entraves para a frutificação da pereira 'Rocha' neste pomar foram a quantidade insuficiente de plantas polinizadoras e o déficit de insetos polinizadores.

Devido ao sistema de autoincompatibilidade gametofítica, que nas Rosáceas é controlado por loco polimórfico (S-lócus) (TAKAYAMA; ISOGAI, 2005; MCCLURE et al., 2011; MATSUMOTO et al., 2012), a pereira possui alta taxa de polinização cruzada, sendo por isso definida como alógama (FREE, 1993; FAORO, 2001). Quando a polinização é insuficiente, observa-se reduzida quantidade de sementes por fruto e, para o desenvolvimento do ovário e dos tecidos adjacentes, a fruta necessita de hormônios produzidos em outras partes da planta ou de aplicações exógenas realizadas pelo fruticultor, uma vez que existem poucas sementes para realizar a produção local destas substâncias (GREENE, 1995; PODESTÁ, 2007).

Comparando-se os resultados dos tratamentos de polinização livre na área com 'Housui' como polinizadora, na safra de 2012/2013, foi possível observar que houve aumento significativo na frutificação efetiva com aplicação de giberelina, passando de baixa para extremamente alta. O mesmo efeito não foi observado no ciclo seguinte (2013/2014), o que indica que a ação deste regulador varia de acordo com as condições climáticas de cada ano. Além desta variação, Silva et al. (2008) citaram que a pereira 'Rocha' apresenta maior frutificação efetiva e melhor formato dos frutos quando estes são oriundos de polinização cruzada, comparativamente com aqueles tratados com giberelinas.

No tratamento de partenocarpia, foi observado aumento significativo na frutificação efetiva, em ambos os ciclos produtivos, passando de $4,16 \%$ para $74,71 \%$ em $2012 / 2013$ e de $0,83 \%$ para $30,0 \%$ em 2013/2014, sem e com o uso da giberelina, respectivamente (Tabela 5 ).

Muitas cultivares de pereiras europeias apresentam a partenocarpia como rota alternativa à autoincompatibilidade gametofítica (MORIYA et al., 2005), sendo que o desenvolvimento partenocárpico pode ser induzido através da aplicação de reguladores de crescimento (SILVA et al., 2008). Luz (2012) observou aumento significativo na frutificação efetiva das cultivares Willians, Packham's Triumph e Rocha com a utilização de diferentes reguladores de crescimento, o qual é variável de acordo com o ingrediente ativo, a concentração e o ciclo produtivo. Outro fator que pode ter interferido para maior frutificação efetiva neste tratamento, é que, com a emasculação das flores, a calda com giberelina atingiu diretamente o ovário, sendo facilitada sua absorção pelo dano provocado no cálice da flor durante a retirada da corola e dos estames.

De acordo com Westwood (1978) e Sedgley e Griffin, (1989), a partenocarpia pode ser estimulativa, sendo necessário existir estímulo decorrente da polinização, ou vegetativa, em que há desenvolvimento do fruto sem polinização. Por vezes, o termo partenocarpia é usado de forma generalizada, descrevendo os frutos sem sementes maduras, mas em muitos casos isso resulta da degeneração das sementes após a fertilização, designando-se este fenômeno como estenoespermocarpia (SEDGLEY; GRIFFIN, 1989; REVERS et al., 2006). Sousa (2012) cita que a cv. Rocha é parcialmente autofértil e que apresenta alguma tendência para a estenoespermocarpia. Portanto, no caso deste tratamento de autopolinização manual com a aplicação de giberelina pode ter ocorrido o crescimento dos tubos polínicos e, isto associado à aplicação de giberelina, pode ter atuado de maneira sinérgica estimulando a estenoespermocarpia. Devido a isto, em áreas com insuficiência de cultivares polinizadoras, a adição de colmeias de abelhas é recomendável, pois mesmo com autopolinizações pode-se promover o aumento da frutificação efetiva na cv. Rocha. 
TABELA 1- Número de grãos de pólen flor ${ }^{-1}$ das cultivares Rocha, Housui e Packham's Triumph, em Bom Retiro-SC, nos ciclos produtivos de 2012/2013 e 2013/2014.

\begin{tabular}{cccc}
\hline \multirow{2}{*}{ Ciclo produtivo } & \multicolumn{3}{c}{ Número de Grãos de pólen flor $^{-1}$} \\
\cline { 2 - 4 } & Rocha & Housui & Packham's Triumph $^{-}$ \\
\hline $\mathbf{2 0 1 2 / 2 0 1 3}$ & $73.968,6 \mathrm{aC}^{*}$ & $233.345,0 \mathrm{aA}$ & $160.921,9 \mathrm{bB}$ \\
$\mathbf{2 0 1 3 / 2 0 1 4}$ & $93.896,3 \mathrm{aC}$ & $164.787,0 \mathrm{bB}$ & $214.963,5 \mathrm{aA}$ \\
\hline CV (\%) & & 34,79 & \\
\hline
\end{tabular}

*Médias seguidas pela mesma letra maiúscula na linha e minúscula na coluna não diferem estatisticamente entre si. Foi aplicado o teste de Tukey, ao nível de 5\% de probabilidade.

TABELA 2- Número médio de óvulos flor ${ }^{-1}$ das cultivares Rocha, Housui e Packham's Triumph em Bom Retiro- SC, em 2012 e 2013.

\begin{tabular}{cccc}
\hline \multirow{2}{*}{ Ciclo produtivo } & \multicolumn{3}{c}{ Número de óvulos flor $^{-1}$} \\
\cline { 2 - 4 } & Rocha & Housui & Packham's Triumph $^{2}$ \\
\hline $\mathbf{2 0 1 2} / \mathbf{2 0 1 3}$ & $8,4 \mathrm{bB}^{*}$ & $9,9 \mathrm{aA}$ & $10,0 \mathrm{aA}$ \\
$\mathbf{2 0 1 3 / 2 0 1 4}$ & $9,5 \mathrm{aA}$ & $9,6 \mathrm{aA}$ & $9,9 \mathrm{aA}$ \\
\hline CV (\%) & & 8,93 & \\
\hline
\end{tabular}

*Médias seguidas pela mesma letra maiúscula na linha e minúscula na coluna não diferem estatisticamente entre si. Foi aplicado o teste de Tukey, ao nível de 5\% de probabilidade.

TABELA 3- Razão pólen/óvulo média de flores das cultivares Rocha, Housui e Packham’s Triumph em Bom Retiro- SC, em 2012 e 2013.

\begin{tabular}{cccc}
\hline \multirow{2}{*}{ Ciclo produtivo } & \multicolumn{3}{c}{ Razão pólen/óvulo } \\
\cline { 2 - 4 } & Rocha & Housui & Packham's Triumph \\
\hline $\mathbf{2 0 1 2 / 2 0 1 3}$ & $9.578,3 \mathrm{aC} *$ & $26.573,9 \mathrm{aA}$ & $16.198,2 \mathrm{bB}$ \\
$\mathbf{2 0 1 3 / 2 0 1 4}$ & $10.248,7 \mathrm{aC}$ & $17.844,5 \mathrm{bB}$ & $21.646,7 \mathrm{aA}$ \\
\hline CV (\%) & & 33,77 \\
\hline
\end{tabular}

*Médias seguidas pela mesma letra maiúscula na linha e minúscula na coluna não diferem estatisticamente entre si. Foi aplicado o teste de Tukey, ao nível de $5 \%$ de probabilidade.

TABELA 4 - Germinação média (\%) de grãos de pólen flor ${ }^{-1}$ das cultivares Rocha, Housui e Packham's Triumph em Bom Retiro-SC, 2012 e 2013.

\begin{tabular}{ccccc}
\hline \multirow{2}{*}{ Ano } & \multicolumn{4}{c}{ Germinação do pólen (\%) } \\
\cline { 2 - 5 } & Rocha & Housui & Packham's Triumph & Média \\
\hline $\mathbf{2 0 1 2}$ & $49,8 \pm 8,6 \mathrm{~ns}$ & $53,4 \pm 3,8$ & $59,6 \pm 2,2$ & $54,2 \mathrm{a}$ \\
$\mathbf{2 0 1 3}$ & $25,3 \pm 6,3$ & $27,0 \pm 5,2$ & $41,6 \pm 4,3$ & $31,3 \mathrm{~b}$ \\
\hline Média & $37,5 \mathrm{~B}$ & $40,2 \mathrm{~B}$ & $50,6 \mathrm{~A}$ & 42,75 \\
\hline
\end{tabular}

Médias seguidas pela mesma letra maiúscula na linha e minúscula na coluna não diferem estatisticamente entre si. ${ }^{\text {ns=Não }}$ significativo. Foi aplicado o teste de Tukey, ao nível de $5 \%$ de probabilidade. CV $=12,77 \%$. 
TABELA 5- Frutificação efetiva (\%) e de frutos colhidos (\%) de acordo com o tratamento de polinização na cv. Rocha, em Bom Retiro-SC, nos ciclos em de 2012/2013 e 2013/2014.

\begin{tabular}{|c|c|c|c|c|c|}
\hline & \multirow[b]{2}{*}{ Tratamento } & \multicolumn{2}{|c|}{$2012 / 2013$} & \multicolumn{2}{|c|}{ 2013/2014 } \\
\hline & & $\begin{array}{c}\text { Frutificação } \\
\text { efetiva 30 } \\
\text { DAP* (\%) }\end{array}$ & $\begin{array}{c}\text { Frutos colhidos } \\
\text { (\%) }\end{array}$ & $\begin{array}{c}\text { Frutificação } \\
\text { efetiva 30 } \\
\text { DAP* (\%) }\end{array}$ & $\begin{array}{l}\text { Frutos } \\
\text { colhidos } \\
\text { (\%) }\end{array}$ \\
\hline \multirow{6}{*}{$\begin{array}{l}\text { SEM } \\
\text { Giberelina }\end{array}$} & 1) Polinização livre (área c/ Housui) & $1,66 \mathrm{c}$ & $0,83 \mathrm{c}$ & $9,16 \mathrm{~cd}$ & $9,17 \mathrm{~cd}$ \\
\hline & 2) Autopolinização espontânea & $0,83 \mathrm{c}$ & $0,83 \mathrm{c}$ & $3,33 \mathrm{~d}$ & $3,33 \mathrm{~d}$ \\
\hline & 3) Partenocarpia & $4,16 \mathrm{c}$ & $1,66 \mathrm{c}$ & $0,83 \mathrm{~d}$ & $0,83 \mathrm{~d}$ \\
\hline & 4) $\mathrm{PCM}^{* *}$ Packham's Triumph & $67,85 \mathrm{a}$ & 58,03 a & 45,83 a & 40,83 a \\
\hline & 5) $\mathrm{PCM}^{* *}$ Housui & 66,37 a & 54,59 a & $35,83 \mathrm{ab}$ & $31,67 \mathrm{ab}$ \\
\hline & 6) Autopolinização manual & $10,97 \mathrm{c}$ & $10,80 \mathrm{c}$ & $1,66 \mathrm{~d}$ & $1,66 \mathrm{~d}$ \\
\hline \multirow{8}{*}{$\begin{array}{l}\text { COM } \\
\text { Giberelina }\end{array}$} & 7) Polinização livre (área c/ Housui) & 65,83 a & $50,00 \mathrm{ab}$ & $12,5 \mathrm{~cd}$ & $10,83 \mathrm{~cd}$ \\
\hline & 8) Autopolinização espontânea & $7,5 \mathrm{c}$ & $6,66 \mathrm{c}$ & $5,00 \mathrm{~d}$ & $4,17 \mathrm{~d}$ \\
\hline & 9) Partenocarpia & $74,71 \mathrm{a}$ & $67,24 \mathrm{ab}$ & $30,00 \mathrm{bc}$ & $29,17 \mathrm{bc}$ \\
\hline & 10) $\mathrm{PCM}^{* *}$ Packham's Triumph & $72,44 \mathrm{a}$ & $68,28 \mathrm{a}$ & $47,4 \mathrm{a}$ & 45,69 a \\
\hline & 11) $\mathrm{PCM}^{* *}$ Housui & $53,49 a b$ & 46,23 a & $55,1 \mathrm{a}$ & 54,31 a \\
\hline & 12) Autopolinização manual & $47,5 \mathrm{~b}$ & $36,28 \mathrm{ab}$ & $15,51 \mathrm{~cd}$ & $15,51 \mathrm{~cd}$ \\
\hline & $\begin{array}{l}\text { 13) Polinização livre (área c/ } \\
\text { Packham's Triumph) }\end{array}$ & $58,33 \mathrm{ab}$ & $52,5 \mathrm{a}$ & $16,07 \mathrm{~cd}$ & $10,71 \mathrm{~cd}$ \\
\hline & CV $(\%)$ & 33,79 & 38,86 & 60,94 & 64,31 \\
\hline
\end{tabular}

Médias seguidas por letras minúsculas diferentes na mesma coluna diferem significativamente, de acordo com o teste de Tukey, $\alpha=0,05$;

* DAP $=$ Dias após a polinização;

** PCM = Polinização cruzada manual.

\section{CONCLUSÕES}

As cvs. Housui e Packam's Triumph produzem pólen em quantidade e com qualidade, mas com variação entre os ciclos produtivos.

'Rocha' apresenta variação no número de óvulos por flor entre os ciclos produtivos.

Flores da cv. Rocha submetidas à polinização cruzada apresentam elevada frutificação efetiva, mesmo sem a aplicação exógena de reguladores de crescimento.

A aplicação de ácido giberélico promove o aumento na frutificação efetiva da pereira 'Rocha' quando não ocorre polinização adequada, mas sua eficácia varia entre ciclos produtivos.

A autopolinização, quando associada com a aplicação de giberelina, estimula a estenoespermocarpia.

\section{REFERÊNCIAS}

ANP - Associação Nacional de Produtores de Pera Rocha. Caderno de especificações da Pera Rocha D.O.P. Portugal, 2009. 13p.

BELL, R. L.; QUAMME, H. A.; LAYNE, R. E. C.; SKIRVIN, R. M. Pears. In: JANICK, J.; MOORE, J. N. Fruit breeding. Tree and tropical fruits. West Lafayette: Purdue University Press, 1996. p.441-514.

BENEDEK, P. Insect pollination of fruit crops. In: NYÉKI,J.; SOLTÉSZ, M. Floral biology of temperate zone fruit trees and small fruits. Budapest: Akadémiai Kiadó, 1996. p.287-340.

CASTRO, B.; MARODIN, G. A. B.; SCHIFINOWITTMANN, M. T.; JUNIOR, A. T.; FERREIRA, P. H. G. Floração, polinização e indução de partenocarpia em pereiras. In: REUNIÃO TÉCNICA DA CULTURA DA PEREIRA, 4., 2012. Palestras... Lages: Universidade do Estado de Santa Catarina, 2012. p.66-87. 
CRUDEN, R. W. Pollen-ovule ratio: a conservative indicator of breeding system in flowering plants. Evolution, Lawrence, v.31, n.1, p. 32-46, 1977.

DANTAS, A. C. M.; PEIXOTO, M. L.; NODARI, R. O.; GUERRA, M. P. Viabilidade do pólen e desenvolvimento do tubo polínico em macieira (Malus spp.). Revista Brasileira de Fruticultura, Jaboticabal, v.27, n.3, p.356-359, 2005.

DECONTI, D.; RIBEIRO, M. F.; RASEIRA, M. C. B.; PETERS, J. A.; BIANCHI, V. J. Caracterização anatômico-fisiológica da compatibilidade reprodutiva de ameixeira-japonesa. Revista Brasileira de Fruticultura, Jaboticabal, v.35, n.3, p.695-703, 2013.

DUMANOGLU, H.; CELIK, M. Pollen production of some pear (Pyrus communis L.) cultivars. Acta Horticulturae, Leuven, v. 367, p. 97-99, 1994. (1)

FAO. FAOSTAT. 2013a. Disponível em: $<\underline{\text { http:// }}$ faostat.fao.org/site/339/default.aspx $>$. Acesso em: 11 jun. 2013.

FAO. FAOSTAT. 2013b. Disponível em: $<\underline{\text { http:// }}$ faostat.fao.org/site/342/default.aspx $>$. Acesso em: 11 jun. 2013.

FAORO, I. D. Biologia reprodutiva da pereira japonesa (Pyrus pyrifolia var. Culta) sob o efeito do genótipo e do ambiente. 2009. 219 f. Tese (Doutorado em Recursos Genéticos Vegetais) Faculdade de Agronomia, Universidade Federal de Santa Catarina, Florianópolis, 2009.

FAORO, I. D. Morfologia e fisiologia. In: EPAGRI. Nashi, a pêra japonesa. Florianópolis: Epagri/Jica, 2001. p. 67-94.

FIORAVANÇO, J. C. A cultura da pereira no Brasil: situação econômica e entraves para o seu crescimento. Informações Econômicas, São Paulo, v. 37 , n. 3 , p. $52-60,2007$. (1)

FREE, J. B. Insect pollination of crops. $2^{\text {nd }}$ ed. London: Academic Press, 1993. 684p. (2)

GONÇALVES, C. X. Viabilidade e compatibilidade de pólen de diferentes genótipos de pereira no Rio Grande do Sul. 2008. Dissertação (Mestrado em Agronomia) - Faculdade de Agronomia, Universidade Federal de Pelotas, Pelotas, 2008.
GREENE, D. W. Thidiazuron effects on fruit set, fruit quality, and return bloom of apples. Horticultural Science, Alexandria, v. 30, n. 6, p.1238-1240, 1995.

GUERRA,M.E.;RODRIGO, J.;LOPESCORRALES, M.; WUNSCH, A. S-RNase genotyping and incompatibility group assignment by PCR and pollination experiments in Japanese plum. Plant Breeding, Berlin, v.128, n.3, p. 304-311, 2009.

IBGE - Instituto Brasileiro de Geografia e Estatística. Pesquisa de orçamentos familiares 2008-2009: aquisição alimentar domiciliar Per capita. Rio de Janeiro: IBGE, 2010.

JACKSON, J.E. Biology of apples and pears. Cambridge: Cambridge University Press, 2003. 488 p.

KEARNS, C. A.; INOUYE, D. W. Techniques for pollination biologists. Niwot: University Press of Colorado, 1993. 583p.

LEITE, D. L.; SOUZA, C. M. Polinização In: NAKASU, B. H.; CENTELLAS-QUEZADA, A.; HERTER, F. G. Pêra: produção. Brasília: Embrapa Informação Tecnológica, 2003. p.23-28.

LUZ, A. R. Fitorreguladores em pereiras europeias: fruit set, produtividade e qualidade de frutos. 2012. Dissertação (Mestrado em Produção Vegetal) - Centro de Ciências Agroveterinárias, Universidade do Estado de Santa Catarina, Lages, 2012.

MATSUMOTO, D.; YAMANE, H.; ABE, K.; TAO, R. Identification of a Skp1-like protein interacting with SFB, the pollen S determinant of the gametophytic self-incompatibility in Prunus. Plant Physiology, Rockville, v. 159, p. 1252-1262, 2012.

MCLURE, B.; CRUZ-GARCIA, F.; ROMERO, C. Compatibility and incompatibility in S-RNase-based systems. Annals of botany, Oxford, v.108, p. 647 658, 2011.

MORIYA, Y.; TAKAI, T.; OKADA, K., ITO, D.; SHIOZAKI, Y.; NAKANISHI, T.; TAKASAKI, T. Parthenocarpy and self and cross-incompatibility in ten European pear cultivars. Journal of the Japanese Society for Horticultural Science, Sakyo-Ku, v.74, n.6, p. 424-430, 2005. 
NAKASU, B. H.; FAORO, I. D. Cultivares. In: NAKASU, B. H.; CENTELLAS-QUEZADA, A.; HERTER, F. G. Pêra: produção. Brasília: Embrapa Informação Tecnológica, 2003. p.29-36.

NYÉKI, J.; SOLTÉSZ, M. Fruit set of pear varieties by open pollination at sites of different ecological conditions. Acta Horticulturae, Leuven, n.475, p.355-365, 1998 .

PETRI，J.L.; COUTO, M.; LEITE, G. B. Monitoramento do frio. Epagri: Estação Experimental de Caçador, 2013. 3p. (Informe Técnico, 6).

PETRI, J. L.; LEITE, G. B.; YASUNOBU, Y. Incidência e fatores do abortamento de gemas em pereira japonesa. Agropecuária Catarinense, Florianópolis, v.14, n.2; p.14-18, 2001.

PODESTA, L. Floración, Polinización y Cuaje. In: OZZI, G. Árboles frutales: ecofisiolgía, cultivo y aprovechamiento. Buenos Aires: Editorial Facultad de Agronomía-Universidade de Buenos Aires, 2007. p 281-305.

REVERS, L. F.; LAMPE, V. S.; OLIVEIRA, P. R. D.; CAMARGO, U. A.; LIMA, J. C. Uso prático de marcadores moleculares para seleção assistida no melhoramento de uvas apirênicas. Revista Brasileira de Fruticultura, Jaboticabal, v.28, n.1, p.104-108, 2006.

SEDGLEY, M.; GRIFFIN,A. R. Sexual reproduction of tree crops. London: Academic Press, 1989. 392p.
SILVA, J. M.; BARBA, N. G.; BARROS, M. T.; TORRES-PAULO, A. Rocha, the pear from Portugal. Acta Horticulturae, Leuven, v.671, p.219-222, 2005.

SILVA, L.; HERRERO, M.; OLIVEIRA, C. M. Effects of gibberellic acid and pollination on fruit set and fruit quality in Rocha pear. Acta Horticulturae, Leuven, v.800, p.199-204, 2008.

SOUSA, R. M. Manejo de pomares de pereira 'Rocha'. In.: RUFATO, L.; MARCON FILHO, J. L.; MUNIZ, J. N. In: REUNIÃO TÉCNICA DA CULTURA DA PEREIRA,4., 2012. Palestras... Lages: Universidade do Estado de Santa Catarina, 2012. p. 22-39.

SOUZA, C. M. Incompatibilidade gametofítica em cultivares de pereira (Pyrus spp.). 1999. Tese (Doutorado em Agronomia) - Faculdade de Agronomia, Universidade Federal de Pelotas, Pelotas, 1999.

SOUZA, C. M.; RASEIRA, M. C. B. Germinação in vitro de pólen de pereira. Agropecuária de Clima Temperado, Pelotas, v.1, n.2, p. 219-223, 1998.

TAKAYAMA, S.; ISOGAI, A. Self-Incompatibility in Plants. Annual Review of Plant Biology, Palo Alto, v.56, p.467-489, 2005.

WESTWOOD, M. N. Temperate zone pomology. San Francisco: W.H. Freeman, 1978. 428p. 